\title{
Analgesic Effects of Oligonol, Acupuncture and Quantum Light Therapy on Chronic Nonbacterial Prostatitis
}

\author{
Hakan Akdere ${ }^{1}$; Ilhan Oztekin ${ }^{2, *}$; Ersan Arda ${ }^{1}$; Tevfik Aktoz ${ }^{1}$; Fatma Nesrin Turan ${ }^{3}$; Kamil \\ Mehmet Burgazli ${ }^{4}$ \\ ${ }_{1}^{1}$ Department of Urology, Medical Faculty, Trakya University, Edirne, Turkey \\ 2 Departments of Anesthesiology and Algology, Medical Faculty, Trakya University, Edirne, Turkey \\ ${ }^{3}$ Department of Biostatistics, Medical Faculty, Trakya University, Edirne, Turkey \\ ${ }^{4}$ Department of Internal Medicine and Angiology, Wuppertal Research and Medical Center, Wuppertal, Germany \\ *Corresponding Author: Ilhan Oztekin, Departments of Anesthesiology and Algology, Medical Faculty, Trakya University, Edirne, Turkey. Tel: +90-2842357641, Fax: +90-2842358096, \\ E-mail: ioztekin@hotmail.com
}

Received: December 10, 2014; Revised: February 12, 2015; Accepted: March 10, 2015

Background: Chronic Nonbacterial Prostatitis (CNBP) is a condition that frequently causes long-term pain and a significant decrease in the quality of life.

Objectives: The present study aimed to examine the analgesic effects of oligonol, acupuncture, quantum light therapy and their combinations on estrogen-induced CNBP in rats.

Materials and Methods: This experimental study was conducted in Edirne, Turkey, using a simple randomized allocation. A total of 90 adult male Wistar rats were randomized into 9 groups of 10 rats each: Group I, control; Group II, CNBP, Group III, oligonol only, Group IV, acupuncture only; Group V, quantum only; Group VI, oligonol + quantum; Group VII, acupuncture + oligonol; Group VIII, quantum + acupuncture; Group IX, acupuncture + quantum + oligonol. Oligonol treatment was given at a dose of $60 \mathrm{mg} /$ day for 6 weeks. Conceptual vessels $(\mathrm{CV}) 3$ and 4 , and bilaterally urinary bladder $(\mathrm{Bl}) 32$ and 34 points were targeted with 1-hour acupuncture stimulation. The quantum light therapy was applied in 5-minute sessions for 6 weeks (3-times/a week). For pain measurements, mechanical pressure was applied to a point $2 \mathrm{~cm}$ distal to the root of the tail to elicit pain and consequent parameters (peak force, latency time of response and total length of measurement) were assessed.

Results: Analgesic effects were observed with all treatment regimens; however, the most prominent median analgesic effect was shown in the quantum light therapy in combination with acupuncture for estrogen-induced $C N B P(P F 1=663.9, P F 2=403.4)(P=0.012)$. Furthermore, we observed that monotherapy with quantum light showed a better analgesic efficacy as compared to oligonol and acupuncture monotherapies $(\mathrm{PF} 1=1044.6, \mathrm{PF} 2=661.2)(\mathrm{P}=0.018, \mathrm{P}=0.008, \mathrm{P}=0.018$; respectively $)$.

Conclusions: All treatment modalities showed a significant analgesic effect on CNBP in rats, being most prominent with the quantum light therapy.

Keywords: Prostatitis; Pain; Rats; Oligonol; Acupuncture; Therapy

\section{Background}

Prostatitis symptoms are the most prevalent urologic problem in men younger than 50 years of age and account for $8 \%$ of all admissions to urologists $(1,2)$. Chronic Nonbacterial Prostatitis (CNBP), also known as Chronic Pelvic Pain Syndrome (CPPS), is the most common form of prostatitis, affecting over $90 \%$ of cases $(3,4)$. Although exact etiology is still unknown, various theories have been proposed regarding potential causative factors, such as urethral stricture, voiding dysfunction, bladder sphincter dyssynergia and bladder neck obstruction (5, 6). Consequently, in the clinical setting, treatment is very challenging and time-consuming.

Polyphenols are abundant antioxidants in our diet, being distributed most widely in plants (7). Laboratory and epidemiological studies showed preventative effects of polyphenol against cardiovascular diseases, can- cers, diabetes, and neurodegenerative disorders (8-11). A study by Shoskes and colleagues showed in their placebo-controlled randomized trial that patient who were treated with quercetin, which is a common flavonoid polyphenol, had a very significant mean improvement in National Institutes of Health (NIH) chronic prostatitis symptom index scores (12). Oligonol is a low-molecularweight polyphenol formulated from lychee and green tea extracts, containing catechin-type monomers and lower oligomers of proanthocyanidin (13). This product was shown to have well-established safety profile for human consumption (13).

Acupuncture is an alternative method widely used in patients with pain refractory to conventional treatment procedures. Proposed mechanisms for its beneficial effects include increase in Endogenous Opioid Peptides

Copyright (C) 2015, Iranian Red Crescent Medical Journal. This is an open-access article distributed under the terms of the Creative Commons Attribution-NonCommercial 4.0 International License (http://creativecommons.org/licenses/by-nc/4.0/) which permits copy and redistribute the material just in noncommercial usages, provided the original work is properly cited. 
(EOPs) such as enkephalins, endorphins or endomorphins and Diffuse Noxious Inhibitory Control (DNIC) (14). In addition to short-term impact, the use of acupuncture has been shown to provide beneficial effects for chronic pain (15). Furthermore, Capodice et al. demonstrated a potential therapeutic role of acupuncture in the treatment of CPPS (16).

A quantum light therapy is a complex therapeutic method in which 4 different electromagnetic beams are used, as follows: First component, super-pulsed coherent laser beams have a potential to not only stimulate circulation of blood and intracellular metabolism but also activate and regulate immunologic and endocrine systems by penetrating deeper tissues as much as $12-13 \mathrm{~cm}$ (17-22). On the contrary, the second component, pulsed noncoherent infrared beams do not penetrate deeper structures as does super-pulsed coherent laser but possess a forceful regulatory impact on both autonomic and central nervous systems (17). The third component is pulsed red light, which has a lower penetration depth than infrared light. It was shown to alleviate the inflammation, especially in articular structures $(17,23)$. Lastly, the idea lying behind the use of constant magnetic field is that this field may work as a barrier against environmental hazardous factors, thus decreasing the required radiation $(17,24)$.

\section{Objectives}

This study aimed to investigate whether the oligonol treatment, acupuncture application, quantum therapy and combination therapies have analgesic effects on CNBP in rats.

\section{Materials and Methods}

\subsection{Animals and Experimental Design}

This experimental study was conducted on 90 rats using a simple randomized design. The study was done in Edirne, Turkey, between the dates of 1 September 2012 to 1 December 2013. Due to understanding of the minimum number of animal use by both international and local ethical committees, we decided to conduct our study with 90 rats (10 rats in each group), which is required for nonparametric tests. Post-hoc power analysis later showed that our study had a sufficient sample size for the preliminary results.

Ninety adult male Wistar rats older than 3 months of age were housed in cages with free access to a standard diet and water. All cages were maintained on a 12/12 light cycle with room temperature maintained at $23^{\circ} \mathrm{C} \pm 1^{\circ} \mathrm{C}$ and humidity of $55 \% \pm 10 \%$. Experiments were carried out with the approval of Animal Experiments Local Ethics Committee (16.08.2012; no: 2012.06.03). The rats were later divided into 9 groups of 10 rats each using the random allocation, as follows:

Group $1=$ Control; $(\mathrm{n}=10)$.
Group 2 = Chronic prostatitis only $(\mathrm{n}=10)$.

Group $3=$ Oligonol treatment $(n=10)$.

Group 4 =Acupuncture application $(\mathrm{n}=10)$.

Group $5=$ Quantum therapy $(\mathrm{n}=10)$.

Group $6=$ Oligonol plus Quantum $(\mathrm{n}=10)$.

Group $7=$ Oligonol plus Acupuncture $(n=10)$.

Group $8=$ Acupuncture plus Quantum $(n=10)$.

Group $9=$ Oligonol plus Acupuncture plus Quantum (n $=10)$.

During the study, 13 rats (one rat in the third, seventh, and ninth group; two rats in the sixth, and eighth group and 3 rats in fourth and fifth group; respectively) died and were excluded from the study. All animals except those in the control group received regular subcutaneous E2 (17 beta-estradiol) injections (Sigma-Aldrich, Steinheim, Germany) for 4 weeks to induce prostatitis. Afterwards, on the 15th day of this treatment, additional dihydrotestosterone (DHT) injections (Sigma-Aldrich, Steinheim, Germany) were given subcutaneously for two weeks. Dihydrotestosterone and E2 were both administered at a dose of $250 \mu \mathrm{g} / \mathrm{kg}$ per day. Oligonol (Quality Of Life Labs, NY, USA) at a dose of $60 \mathrm{mg} / \mathrm{kg} /$ day was applied for 6 weeks through oral feeding tube via dilution with water. All acupunctural procedures were performed under anesthesia with an intramuscular injection of ketamine and xylazine (50 mg/kg and $5 \mathrm{mg} / \mathrm{kg}$, respectively). Steel acupuncture needles (Hua Long Company, China) with dimensions of $0.20 \times 13 \mathrm{~mm}$ were applied in 1-hour daily sessions for 6 weeks (3-times/a week) at conceptual vessel points 3 and 4, and bilaterally urinary bladder (Bl) 32 and 34 points by a professional acupuncturist.

The RIKTA (Type 04/4) magnetic infrared laser therapy Device (Milta PKP-GIT, Moscow, Russia) was used in quantum therapy groups after routine anesthetic protocols. First, 5-minute daily sessions for 3 days/week in 6 weeks were carried out. Active application areas of $4 \mathrm{~cm}^{2}$ to suprapubic, urinary bladder, anterior penile, and bilateral femoral artery regions were targeted with a laser pulse strength of 12 watts. Additionally, a Douche emitter with the laser pulse strength of 30 watts was also targeted to active circular application area of $20 \mathrm{~cm}^{2}$ to midperineum region between testicles and anus. Table 1 shows components and properties of the quantum light therapy.

\subsection{Assessment of the Pain}

A substantial amount of existing data has led researchers to view CPP as a condition that involves variable degrees of neuropathic pain (25). Therefore, mechanical pressure was applied to a point $2 \mathrm{~cm}$ distal to the root of the tail to elicit pain and assess pain response. For this purpose, a Pressure Application Measurement (PAM) device (Ugo Basile, Gemonio, Italy) with a paw transducer applicator was used to produce a pressure effect on the tail and to assess the tail reaction (i.e. pain threshold). The following pain measurement parameters were recorded on day 1 and 42 in awake rats: 1) peak force in 
Akdere H et al.

\begin{tabular}{lc}
\hline Table 1. Components of the Quantum Light Therapy & \\
\hline Variable & Value \\
\hline Wavelength of Pulsating Broadband Infrared Radiation & $860-960 \mathrm{~nm}$ \\
Wavelength of pulsating broadband red radiation & $40-740 \mathrm{~nm}$ \\
Wavelength of impulsive infrared laser radiation & $890-910 \mathrm{~nm}$ \\
Frequency setting & $50 \mathrm{~Hz}$ \\
$\begin{array}{l}\text { Frequency of red light radiation } \\
\text { Magnetic Induction }\end{array}$ & $2 \mathrm{~Hz}$ \\
$\begin{array}{l}\text { Time of radiation } \\
\text { Power supply }\end{array}$ & $35 \pm 10 \mathrm{mTl}$ \\
$\begin{array}{l}\text { Frequency } \\
\text { Power consumed from an electric network }\end{array}$ & $5 \mathrm{~min}$ \\
$\begin{array}{l}\text { Power } \\
\text { Beam area at the skin }\end{array}$ & $\begin{array}{l}\text { Alternating current } \\
\text { Anatomical location }\end{array}$ \\
& $50 / 60 \mathrm{~Hz}$ \\
\hline
\end{tabular}

\begin{tabular}{|c|c|c|c|c|c|c|c|}
\hline Group & $\begin{array}{c}\text { Number of } \\
\text { Rats at the End } \\
\text { of the Study }\end{array}$ & $\begin{array}{c}\text { Peak Force 1, G Me- } \\
\text { dian (BCa } 95 \% \text { IQR) }\end{array}$ & $\begin{array}{l}\text { Peak Force 2, G Me- } \\
\text { dian (BCa } 95 \% \text { CI) }\end{array}$ & $\begin{array}{c}\text { T-1 B, S Median } \\
(\text { BCa } 95 \% \text { CI })\end{array}$ & $\begin{array}{l}\text { T-1 A, S Median } \\
\text { (BCa } 95 \% \text { CI) }\end{array}$ & $\begin{array}{l}\text { T-2 B, S Median } \\
\text { (BCa } 95 \% \text { CI })\end{array}$ & $\begin{array}{c}\text { T-2 A, S Median } \\
\text { (BCa } 95 \% \text { CI) }\end{array}$ \\
\hline Control & 10 & $992.7(113.1-764.1)$ & $456.2(59.27-419.87)$ & $4.12(4.27-6.82)$ & $5.23(2.92-6.15)$ & $5.38(5.05-6.88)$ & $6.23(2.2-8.6)$ \\
\hline $\begin{array}{l}\text { Chronic } \\
\text { Prostatis }\end{array}$ & 10 & $831.3(82.5-302.5)$ & $519.15(174.7-417.54)$ & $8.82(0.70-7.94)$ & $3.1(2.2-5.5)$ & $9.10(0.73-8)$ & $6.5(1.2-4.3)$ \\
\hline Oligonol & 9 & $1054.7(95.4-378.7)$ & $371.9(80.31-453.05)$ & $8.25(3.75-7.07)$ & $5.8(5.8-8.1)$ & $8.78(3.23-8.02)$ & $6.8(3.6-7.6)$ \\
\hline Acupuncture & 7 & $1096.4(45.7-451.7)$ & $381.7(198.12-365.5)$ & $8.0(4.80-7.66)$ & $4(4.1-10.3)$ & $10.15(3.58-6.44)$ & $8.3(6.5-11.3)$ \\
\hline Quantum & 7 & $1044.6(91.0-186.1)$ & $661.2(312.9-550.6)$ & $8.0(3.02-6.35)$ & $3(3.14-8.94)$ & $8.5(2.85-6.5)$ & $7.1(4.9-8.5)$ \\
\hline $\begin{array}{l}\text { Oligonol + } \\
\text { Quantum }\end{array}$ & 8 & $911.5(212.0-653.6)$ & $659.6(98.5-360)$ & $11.50(2.96-6.86)$ & $3.8(1.7-8.4)$ & $12.54(2.4-6.32)$ & $7.6(4-7.6)$ \\
\hline $\begin{array}{l}\text { Acupuncture + } \\
\text { Oligonol }\end{array}$ & 9 & $1041.7(190.4-823.8)$ & $371.4(18.07-165.6)$ & $5.20(1.23-7.19)$ & $5.7(0.9-4.6)$ & $9.05(0.75-7.42)$ & $6.05(0.9-4.7)$ \\
\hline $\begin{array}{l}\text { Quantum + } \\
\text { Acupuncture }\end{array}$ & 8 & $663.9(248.3-536.5)$ & $403.4(36.5-64.7)$ & $3.75(0.92-10.51)$ & $8.5(0.5-5.74)$ & $4.05(1.45-10.20)$ & $9.2(1.7-5.3)$ \\
\hline $\begin{array}{l}\text { Quantum + } \\
\text { Oligonol + } \\
\text { Acupuncture }\end{array}$ & 9 & $533.9(166.0-310.2)$ & $388(0.9-292.1)$ & $6.40(2.23-7.30)$ & $5.42(1.5-8.8)$ & $6.7(1.8-6.01)$ & $6.3(2.2-8.4)$ \\
\hline
\end{tabular}

grams, 2) latency time of animal response (T1) in seconds, and 3) total length of the measurement (T2) in seconds. For each parameter, 3 measurements were done and the arithmetic mean for each parameter was determined.

\subsection{Statistical Analysis}

Data are expressed as mean \pm SD. Normality of distribution was tested using the one-sample KolmogorovSmirno test. Data were analyzed using the Kruskal-Wallis and post-hoc Bonferroni-corrected Mann-Whitney tests.
Intragroup comparisons were evaluated by the Wilcoxon test. Statistical analyses were conducted using SPSS version 20.0 (SPSS, Chicago, IL, USA). P value less than 0.05 was considered statistically significant.

\section{Results}

Statistically significant pre-treatment difference existed between the groups as follows: between control versus quantum $(\mathrm{P}=0.045)$ and quantum plus acu- 
puncture group $(\mathrm{P}=0.001)$, between chronic prostatitis versus oligonol plus quantum groups $(\mathrm{P}=0.002)$ and acupuncture plus oligonol $(\mathrm{P}=0.004)$ and quantum plus acupuncture $(\mathrm{P}=0.001)$ and quantum plus oligonol plus acupuncture group $(P=0.002)$, between quantum versus oligonol plus quantum $(\mathrm{P}=0.011)$ and acupuncture plus oligonol $(\mathrm{P}=0.004)$ and quantum plus oligonol plus acupuncture $(\mathrm{P}=0.01)$, between oligonol plus quantum and quantum plus acupuncture $(\mathrm{P}$ $=0.001)$, between oligonol and quantum plus acupuncture $(\mathrm{P}=0.012)$, between quantum plus oligonol plus acupuncture and quantum plus acupuncture groups $(\mathrm{P}$ $=0.001$ ), between acupuncture plus oligonol and quantum plus acupuncture $(\mathrm{P}=0.001)$ and lastly between acupuncture and quantum plus acupuncture groups $(P=0.004)$ (Figure 1). Furthermore, regarding posttreatment peak force measurements, rats treated with oligonol only had higher peak forces compared with those in the control group $(\mathrm{P}=0.022)$, acupuncture only $(\mathrm{P}=0.002)$, quantum only $(\mathrm{P}=0.002)$ and quantum plus acupuncture groups $(\mathrm{P}=0.001)$, oligonol plus quantum $(\mathrm{P}=0.012)$, acupuncture plus oligonol $(\mathrm{P}=0.019)$ (Table 2). Additionally, rats in the chronic prostatitis group had higher post-treatment values compared with rats in the quantum plus acupuncture group $(\mathrm{P}=0.041)$.

A significant decrease in peak force measured at the tail was noted in all 9 groups when compared to the baseline $(\mathrm{P}=0.005, \mathrm{P}=0.005, \mathrm{P}=0.008, \mathrm{P}=0.018, \mathrm{P}=0.018, \mathrm{P}=$ $0.012, \mathrm{P}=0.008, \mathrm{P}=0.012$ and $\mathrm{P}=0.008$; respectively) (Figure 1).

Figure 1. Peak Force 1 (Before Treatment) and 2 (After Treatment) Values

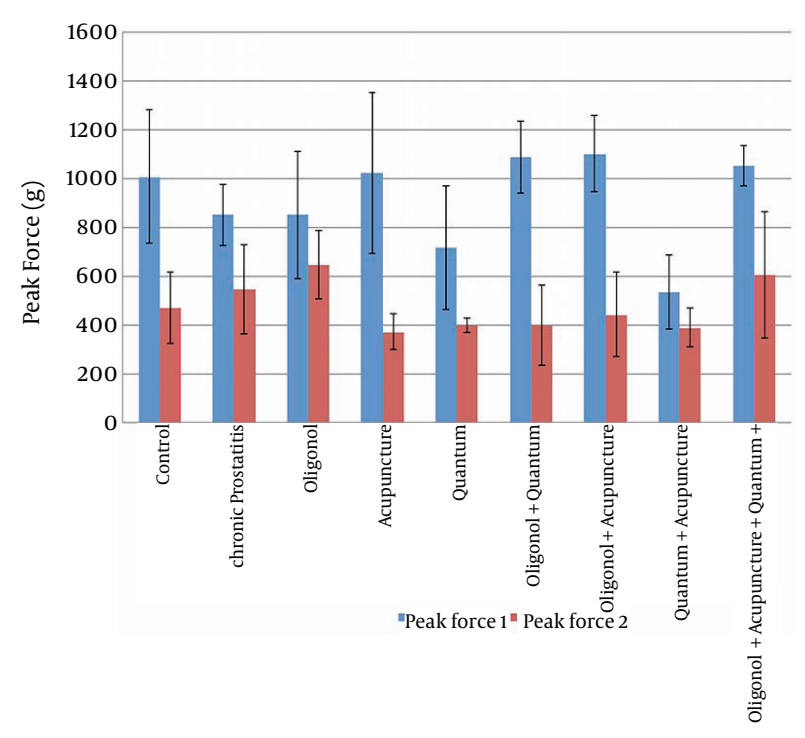

Data Expressed as Mean \pm SD.
Figure 2. Latency Time (A) and Total Lengths (B) of the Rat Response Through Tail Stimulation

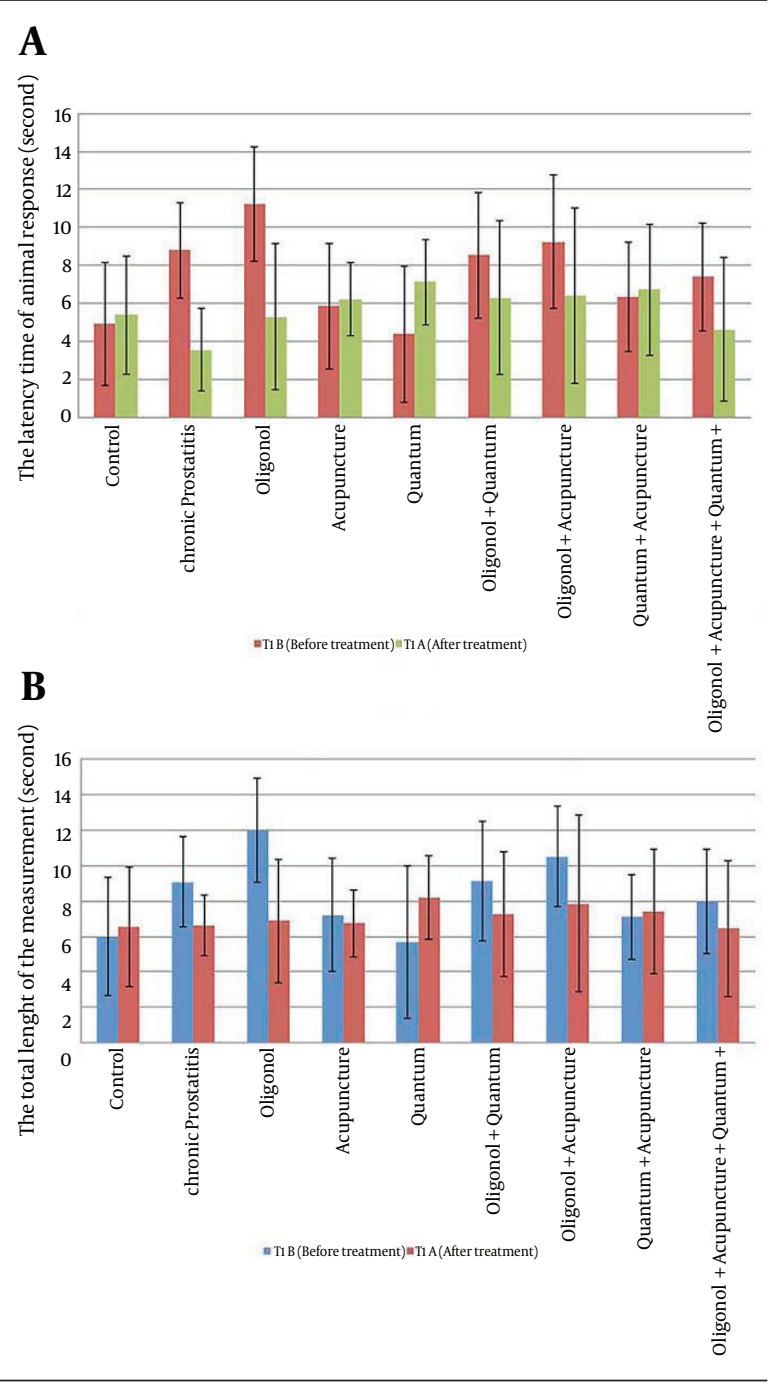

Data expressed as mean \pm SD.

There were significant pre-treatment differences also in $\mathrm{T} 1$ (latency time of the rat response) values between control versus chronic prostatitis $(\mathrm{P}=0.014)$ and oligonol plus quantum $(\mathrm{P}=0.026)$ and acupuncture plus oligonol $(P=0.018)$ and oligonol $(P=0.003)$, between chronic prostatitis and quantum $(\mathrm{P}=0.011)$, between quantum versus quantum plus oligonol $(\mathrm{P}=0.028)$ and acupuncture plus oligonol $(\mathrm{P}=0.007)$, between oligonol versus acupuncture $(\mathrm{P}=0.013)$ and quantum $(\mathrm{P}=0.005)$ and quantum plus acupuncture $(\mathrm{P}=0.007)$, and quantum plus acupuncture plus oligonol groups $(\mathrm{P}=0.024)$. Posttreatment $\mathrm{T} 1$ values were comparable among the groups.

It was demonstrated that there was a significant decrease in $\mathrm{T} 1$ from baseline in chronic prostatitis and oligonol groups $(\mathrm{P}=0.005, \mathrm{P}=0.008$; respectively). Moreover, similar to T1 results, a significant pre-treatment difference was shown in $\mathrm{T} 2$ values between control ver- 
sus oligonol $(\mathrm{P}=0.004)$ and oligonol plus acupuncture $(\mathrm{P}=0.022)$, between oligonol plus acupuncture versus quantum $(\mathrm{P}=0.039)$ and quantum plus acupuncture $(\mathrm{P}$ $=0.027)$, between oligonol versus quantum $(P=0.007)$ and acupuncture $(\mathrm{P}=0.023)$ and quantum plus acupuncture groups $(\mathrm{P}=0.005)$ and oligonol plus quantum plus acupuncture $(\mathrm{P}=0.019)$. Post-treatment $\mathrm{T} 2$ values did not differ significantly between the groups. Within group comparisons of $\mathrm{T} 2$ levels showed a significant decrease in chronic prostatitis $(\mathrm{P}=0.05)$ and oligonol only group $(\mathrm{P}$ $=0.008$ ) (Figure 2 ).

\section{Discussion}

The underlying etiology of CNBP remains elusive. However, certain factors, such as anatomic problems and hormonal imbalance have been shown to play a role in its development (26). Accordingly, it was previously shown that E2 and DHT treatment could produce CNBP. Wistar rats are especially very prone to prostatitis, administration of E2 leads to inflammation of prostate gland and additional testosterone helps to prevent tissue atrophy (27). We thus treated Wistar rats with E2 and DHT combination as described above to induce the development of CNBP.

Pain associated with CNBP has been reported to involve variable degrees of a neuropathic characters (25). In this study, paw probe and a PAM device were used to induce tail pain in rats with CNBP to allow a quantitative assessment of pain. Assessments at the second time point showed a significant decrease in peak force in all groups with regard to neuropathic pain. The decrease in the second measurement in the control group was probably due to ageing, which is associated with spontaneous development of CNBP in Wistar rats (28). Significant differences between groups at pre-treatment and post-treatment assessments could arise from a low number of samples or inequality in the number of samples resulting from the death of a certain number of animals due to anesthesia or some other undefined causes. However, the assessment of the within group changes in peak force values between pre-treatment and post-treatment time points showed that the quantum plus oligonol plus acupuncture and oligonol plus quantum groups had the greatest analgesic effect. In addition, it can be argued that the quantum therapy showed a more significant analgesic effect compared to acupuncture and oligonol. The change in T1 and T2 between pre- and post-treatment assessments showed a decrease for oligonol and an increase for quantum, supporting our view.

Quantum light therapy, a unique form of magneto-laser therapy, is a combined treatment modality that involves different laser beams and magnetic field. Magneto-laser therapies have been investigated by various studies and shown to exert beneficial effects on wide range of different disorders such as vasomotor rhinitis, cardiac arrhythmias, osteoarthritis, and nonbacterial prostatitis (29-31). To date, 3 studies investigated the efficacy of magnetolaser therapy of patients with CNBP, all of which demon- strated beneficial effects (32-34). One of these studies, in which standard therapy versus standard therapy plus magnetolaser therapy were compared reported a significant improvement in quality of life, urinary tract symptoms and pain in magnetolaser combined group, which is analogous with our experimental findings (33).

Polyphenols are the most abundant antioxidants in our diet and known to have protective effects against cancer, diabetes and cardiovascular diseases (7-11). For CNBP, one of the polyphenols named quercetin, has been found to be effective in improvement of NIH chronic prostatitis symptoms index scores (12). Moreover, specifically, oligonol, which is a low-molecular-weight oligomerized polyphenol has been shown to possess strong anti-inflammatory activity (35). However, in our study, oligonol did not appear to be as effective as the quantum therapy in relieving pain associated with prostatitis.

There is convincing evidence that acupuncture therapy is effective as an analgesic for both acute and chronic pain (15). In addition to analgesia, acupuncture has antiinflammatory properties $(36,37)$. Several clinical studies have investigated the efficacy of acupuncture for the treatment on the symptoms of CNBP. Within these studies acupuncture treatment was shown to improve chronic pelvic pain syndrome symptoms $(38,39)$. In the present study, we targeted the most frequently preferred acupuncture points (CV 3 and 4; bilaterally B1 32 and 34). The more evident effect in lowering the peak force was found with acupuncture as compared with oligonol and quantum therapies-thus suggesting that acupuncture may have a lower analgesic efficacy. According to our findings, it may also be suggested that combining acupuncture with quantum therapy may result in a synergistic effect.

This study has faced several limitations that are to be mentioned. First, because there were no similar studies in the literature, we determined our study size according to the understanding of minimal number of animal in the experimental research. Second, we aimed to investigate the effects of not only different treatments but also their different combinations. Therefor our study included a relatively high number of groups. Lastly, numerous rats died in different groups due to long-term study protocols. For this reason, equal number of distribution was not achieved.

The main strengths of the present study have already been indicated. First of all, to our knowledge, this is the first such study in which the effects of the above-mentioned treatment modalities were investigated on CNBP; thus, this study provides preliminary results for future large-sample studies. Second, these novel treatment strategies may have an important role in a clinical setting since current pharmacological approaches are not sufficient for CNBP-related neuropathic pain. Additionally, we used PAM device, which is a novel device strongly recommended for quantification of neuropathic pain. Accordingly, we believe that our findings will significantly contribute to the existing literature. 
In summary, in spite of the fact that the analgesic effects were observed with all treatment regimens; however, the most prominent median analgesic effect was shown in the quantum light therapy in combination with acupuncture for estrogen-induced CNBP $(\mathrm{P}=0.012)$. Furthermore, we observed that monotherapy with quantum light showed a better analgesic efficacy as compared to oligonol and acupuncture monotherapies (respectively; $\mathrm{P}=0.018, \mathrm{P}=0.008, \mathrm{P}=0.018)$. It can be however thought that the combination therapies, such as quantum light plus acupuncture have a synergism. Further studies are warranted in order to straighten our results.

\section{Authors' Contributions}

Study concept and design: Ilhan Oztekin, Hakan Akdere; Acquisition of data: Ilhan Oztekin; Analysis and interpretation of data: Hakan Akdere, Ilhan Oztekin; Drafting of the manuscript: Ilhan Oztekin, Tevfik Aktoz, Ersan Arda, Kamil Mehmet Burgazli; Critical revision of the manuscript for important intellectual content: Tevfik Aktoz, Ersan Arda, Kamil Mehmet Burgazli; Statistical analysis: Fatma Nesrin Turan; Administrative, technical, and material support: Ilhan Oztekin, Hakan Akdere; Study supervision: Ilhan Oztekin.

\section{Funding/Support}

This study was funded and supported by the scientific research and project development unit of Trakya University in Turkey.

\section{References}

1. Krieger JN, Nyberg LJ, Nickel JC. NIH consensus definition and classification of prostatitis. JAMA.1999;282(3):236-7.

2. Litwin MS, McNaughton-Collins M, Fowler FJJ, Nickel JC, Calhoun EA, Pontari MA, et al. The National Institutes of Health chronic prostatitis symptom index: development and validation of a new outcome measure. Chronic Prostatitis Collaborative Research Network. J Urol. 1999;162(2):369-75.

3. Potts JM, O'Dougherty E. Pelvic floor physical therapy for patients with prostatitis. Curr Urol Rep. 2000;1(2):155-8

4. Gurunadha Rao Tunuguntla HS, Evans CP. Management of prostatitis. Prostate Cancer Prostatic Dis. 2002;5(3):172-9.

5. Nickel JC. Prostatitis: evolving management strategies. Urol Clin North Am. 1999;26(4):737-51.

6. Kaplan SA, Santarosa RP, D'Alisera PM, Fay BJ, Ikeguchi EF, Hendricks J, et al. Pseudodyssynergia (contraction of the external sphincter during voiding) misdiagnosed as chronic nonbacterial prostatitis and the role of biofeedback as a therapeutic option. J Urol.1997;157(6):2234-7.

7. Scalbert A, Johnson IT, Saltmarsh M. Polyphenols: antioxidants and beyond. Am J Clin Nutr. 2005;81(1 Suppl):215S-7S

8. Grove KA, Lambert JD. Laboratory, epidemiological, and human intervention studies show that tea (Camellia sinensis) may be useful in the prevention of obesity. J Nutr. 2010;140(3):446-53.

9. Lambert JD, Hong J, Yang GY, Liao J, Yang CS. Inhibition of carcinogenesis by polyphenols: evidence from laboratory investigations. Am J Clin Nutr. 2005;81(1 Suppl):284S-91S.

10. Higdon JV, Frei B. Tea catechins and polyphenols: health effects, metabolism, and antioxidant functions. Crit Rev Food Sci Nutr. 2003;43(1):89-143.

11. Moriwaki Y, Okuda C, Yamamoto A, Ka T, Tsutsumi Z, Takahashi $S$, et al. Effects of Oligonol $®$, an oligomerized polyphenol formulated from lychee fruit, on serum concentration and urinary excretion of uric acid. J Funct Foods. 2011;3(1):13-6.

12. Shoskes DA, Zeitlin SI, Shahed A, Rajfer J. Quercetin in men with category III chronic prostatitis: a preliminary prospective, double-blind, placebo-controlled trial. Urology. 1999;54(6):960-3

13. Fujii H, Nishioka H, Wakame K, Magnuson BA, Roberts A. Acute, subchronic and genotoxicity studies conducted with Oligonol, an oligomerized polyphenol formulated from lychee and green tea extracts. Food Chem Toxicol. 2008;46(12):3553-62.

14. Kawakita K, Okada K. Acupuncture therapy: mechanism of ac tion, efficacy, and safety: a potential intervention for psychogenic disorders? Biopsychosoc Med. 2014;8(1):4.

15. Vickers AJ, Linde K. Acupuncture for chronic pain. JAMA 2014;311(9):955-6.

16. Capodice JL, Jin Z, Bemis DL, Samadi D, Stone BA, Kapan S, et al. A pilot study on acupuncture for lower urinary tract symptoms related to chronic prostatitis/chronic pelvic pain. Chin Med. 2007;2:1.

17. Fyodorov Y. Quantum Therapy and the Prevention of a WideRange of Diseases. 10 edMoscow, Russia: Quantum Medicine Association; 2007.

18. Alves AN, Fernandes KP, Melo CA, Yamaguchi RY, Franca CM, Teixeira DF, et al. Modulating effect of low level-laser therapy on fibrosis in the repair process of the tibialis anterior muscle in rats. Lasers Med Sci. 2014;29(2):813-21.

19. Wu JY, Chen CH, Yeh LY, Yeh ML, Ting CC, Wang YH. Low-power laser irradiation promotes the proliferation and osteogenic differentiation of human periodontal ligament cells via cyclic adenosine monophosphate. Int J Oral Sci. 2013;5(2):85-91.

20. Ebrahimi T, Moslemi N, Rokn A, Heidari M, Nokhbatolfoghahaie $\mathrm{H}$, Fekrazad R. The influence of low-intensity laser therapy on bone healing. J Dent (Tehran). 2012;9(4):238-48.

21. Assis L, Moretti AI, Abrahao TB, Cury V, Souza HP, Hamblin MR, et al. Low-level laser therapy $(808 \mathrm{~nm})$ reduces inflammatory response and oxidative stress in rat tibialis anterior muscle after cryolesion. Lasers Surg Med. 2012;44(9):726-35.

22. Casalechi HL, Leal-Junior EC, Xavier M, Silva JAJ, de Carvalho Pde $\mathrm{T}$, Aimbire F, et al. Low-level laser therapy in experimental model of collagenase-induced tendinitis in rats: effects in acute and chronic inflammatory phases. Lasers Med Sci. 2013;28(3):989-95.

23. Dahan S. Laser and intense pulsed light management of couperose and rosacea. Ann Dermatol Venereol. 2011;138 Suppl 3:219-22.

24. Kupriianova TA, Markov BP, Vilkova LA, Barabash AG. [The use of a permanent magnetic field in the combined treatment of lichen ruber planus of the oral mucosa]. Stomatologiia (Mosk). 1989;68(5):33-4.

25. Strauss AC, Dimitrakov JD. New treatments for chronic prostatitis/chronic pelvic pain syndrome. Nat Rev Urol. 2010;7(3):127-35.

26. Rakel D. Integrative Medicine.Philadelphia: Saunders;2012.

27. Naslund MJ, Strandberg JD, Coffey DS. The role of androgens and estrogens in the pathogenesis of experimental nonbacterial prostatitis. J Urol.1988;140(5):1049-53.

28. Fujii H, Sun B, Nishioka H, Hirose A, Aruoma OI. Evaluation of the safety and toxicity of the oligomerized polyphenol Oligonol. Food Chem Toxicol. 2007;45(3):378-87.

29. Fedorov AA, Riabko EV, Gromov AS. [The use of magnetic-laser therapy in the combined treatment of osteoarthrosis in workers exposed to inorganic fluoride compounds]. Vopr Kurortol Fizioter Lech Fiz Kult. 2010(4):20-2.

30. Mamedov AF. [Clinical effectiveness of magnetolaser therapy of vasomotor rhinitis]. Vestn Otorinolaringol.1991(3):60-3.

31. Budnar LN, Antiuf'ev VF, Oranskii IE, Bekhter TV. [The effect of exposure to magnetics and lasers on the clinical status and the electrophysiological indices of the heart in patients with cardiac arrhythmias]. Vopr Kurortol Fizioter Lech Fiz Kult. 1996(2):5-8.

32. Shangichev AV. [Biologically controlled magnetolaser therapy of chronic abacterial prostatitis]. Vopr Kurortol Fizioter Lech Fiz Kult. 2009(3):37-40.

33. Kogan MI, Shangichev AV, Belousov ,I. [Efficacy of magnetolaser therapy of patients with an inflammatory form of chronic abacterial prostatitis]. Urologiia. 2010(2):42-4.

34. Reshetov PP, Reshetov SP, Sedov ON, Bol'shakov DL. [Magnetolaser therapy in chronic prostatitis]. Vopr Kurortol Fizioter Lech Fiz Kult. 2004(6):41. 


\section{Akdere H et al.}

35. Lee JB, Shin YO. Oligonol supplementation affects leukocyte and immune cell counts after heat loading in humans. Nutrients. 2014;6(6):2466-77.

36. Yang ZX, Chen PD, Yu HB, Pi M, Luo WS, Zhuo YY. Study strategies for acupuncture treatment of chronic nonbacterial prostatitis. Zhong Xi Yi Jie He Xue Bao. 2012;10(3):293-7.

37. Capodice JL, Bemis DL, Buttyan R, Kaplan SA, Katz AE. Complementary and alternative medicine for chronic prostatitis/chron- ic pelvic pain syndrome. Evid Based Complement Alternat Med. 2005;2(4):495-501.

38. Lee SW, Liong ML, Yuen KH, Leong WS, Chee C, Cheah PY, et al Acupuncture versus sham acupuncture for chronic prostatitis/ chronic pelvic pain. Am J Med. 2008;121(1):79 e1-7.

39. Lee SH, Lee BC. Electroacupuncture relieves pain in men with chronic prostatitis/chronic pelvic pain syndrome: three-arm randomized trial. Urology. 2009;73(5):1036-41. 